\title{
Association between diabetes complications and leukocyte counts in Iranian patients
}

\author{
This article was published in the following Dove Press journal: \\ Journal of Inflammation Research \\ 23 January 2012 \\ Number of times this article has been viewed
}

\author{
Sedigheh Moradi' \\ Scott Reza Jafarian Kerman² \\ Farzaneh Rohani' \\ Fereshteh Salari ${ }^{2}$ \\ 'Endocrine and Metabolism Research \\ Center (Firouzgar), Hemmat Campus, \\ Tehran University of Medical Sciences, \\ Tehran, Iran, ${ }^{2}$ Scientific Students \\ Research Committee, Tehran \\ University of Medical Sciences, \\ Tehran, Iran
}

Background: The long term complications of diabetes can be fatal. They are also renowned for being an economic burden. Previous studies have demonstrated a relationship between inflammatory markers and complications of diabetes. The objective of this study was to evaluate the relationship between leukocyte counts and these complications.

Methods: The study included 184 patients diagnosed with type 2 diabetes. The study was carried out in Iran during 2007 and 2008. Data collected on the subjects were as follows: age, gender, weight, height, blood pressure, smoking history, lipid profile including low density lipoprotein (LDL), high density lipoprotein (HDL), total cholesterol, triglycerides, and leukocyte count, albuminuria, and retinopathy. Furthermore, information on cardiac history for 100 patients was collected. The subjects were split into two groups according to their leukocyte levels: low $\left(\leq 7000 / \mathrm{mm}^{3}\right)$ and high $\left(>7000 / \mathrm{mm}^{3}\right)$; and then analyzed by Student's $t$-test or Mann-Whitney U-test as appropriate.

Results: The average leukocyte count in these patients was $7594 \pm 1965 / \mathrm{mm}^{3}$. Leukocyte count was significantly different in patients with and without retinopathy and albuminuria $(P<0.0001)$. According to this analysis, a leukocyte count of $6750 / \mathrm{mm}^{3}$ with a sensitivity of $80.2 \%$ and a specificity of $56.4 \%$, and a count of $7550 / \mathrm{mm}^{3}$ with a sensitivity of $63.2 \%$ and a specificity of $74.6 \%$ indicated at least one diabetes complication.

Conclusion: An elevated leukocyte count even within the normal range was associated with chronic complications in type 2 diabetes.

Keywords: leukocytes, diabetes complications, inflammation

\section{Introduction}

Type 2 diabetes mellitus is a chronic illness that requires appropriate medical care and patient education in a self-management program to reduce long term complications. ${ }^{1}$ It is characterized by hyperglycemia and other metabolic disorders resulting from insulin resistance that is responsible for pathophysiologic changes in various body organs. ${ }^{2}$ It is estimated that there will be about 300 million individuals fighting diabetes by the year 2025 and, according to World Health Organization statistics, each diabetic patient spends about three times more money on his or her health than a person without diabetes. ${ }^{3}$ The long term complications that result from poor glycemic control contribute substantially to the morbidity, mortality, and economic burden of diabetes. ${ }^{4}$

Diabetes is the main cause of blindness and end stage renal disease in adults. ${ }^{5-7}$ Furthermore, most evidence indicates that atherosclerosis progresses faster in diabetic patients than in people without diabetes. ${ }^{8}$ Some investigations show that lowering the serum glucose level will delay the occurrence of complications. ${ }^{9,10}$
Correspondence: Sedigheh Moradi Institute of Endocrine and Metabolism (Firouzgar), Valadi St, Valiasr Ave,

Tehran I5937487I I, Iran

Tel +989121863958

Fax +982I 24202448

Email s-moradi@tums.ac.ir which permits unrestricted noncommercial use, provided the original work is properly cited. 
There are some conventional and important risk factors that affect the development of complications of diabetes, but they cannot fully explain this excess risk. In recent studies the focus was on inflammatory factors. These studies determined that higher C-reactive protein, fibrinogen, and leukocyte count were related to higher risk of cardiac events. ${ }^{11-13}$ It was shown that leukocytes play an important role in the progression of diabetes complications. ${ }^{14}$ Leukocytes can be activated by glycation end products, oxidative stress, angiotensin II resulting from hyperglycemia, and can produce factors like tumor necrosis factor- $\alpha$ and interleukin $\beta 1$ that involve chronic diabetes complication pathogenesis. ${ }^{15-19}$

Thus, early diagnosis and treatment of diabetes can prevent or reduce the development of complications. Furthermore, we need cost benefit and in reach methods to identify those patients who need more care. Therefore, this study was carried out to investigate the association of leukocyte count as a biomarker for inflammation with microvascular and macrovascular complications in diabetic individuals. Leukocyte count is a cost effective and available laboratory test that can show inflammatory activity.

\section{Material and methods}

Patients diagnosed with type 2 diabetes in Iran during the years 2007 and $2008(n=184)$ were included in our analytical cross sectional study. All diagnoses were based on American Diabetes Association diagnostic criteria. ${ }^{20}$ All patients' files including age, gender, weight, height, blood pressure, smoking history, lipid profile including low density lipoprotein (LDL), high density lipoprotein (HDL), total cholesterol, and triglycerides, and leukocyte count, albuminuria, and retinopathy were made available. Furthermore, information on cardiac histories was collected for 100 of the patients. Patients with any kind of malignancy, infection in the past 2 weeks, or chronic inflammatory diseases such as rheumatoid arthritis in their medical history were excluded.

All Biochemical assays were carried out in the Institute of Endocrinology and Metabolism Laboratory, Tehran, Iran. Total cholesterol, HDL, and triglycerides were measured by photometric assay. Intra- and inter-assay coefficients of variation for all tests were less than 2\% (Teif Azmoon Pars Co, Tehran, Iran), and LDL was calculated with the use of Friedwald formula.

Albuminuria was diagnosed from a 24-hour urine collection albumin measurement. Albuminuria was defined based on urinary albumin excretion more than $30 \mathrm{mg} / 24 \mathrm{~h}$. Retinopathy was detected and differentiated by an ophthalmologist by funduscopy and was defined based on nonproliferative and proliferative retinopathies. Cardiac events were filed by the opinion of a cardiologist, electrocardiogram or history of coronary care unit admission at least 2 years after diagnosis of diabetes.

\section{Statistical analysis}

All data were analyzed by SPSS software for Windows (v16.0; SPSS, Chicago, IL). Data were first evaluated for log normal distribution by Kolmogorov-Smirnov test and were described with mean \pm standard deviation. Leukocyte count results were split into two groups as follows: low ( $\leq 7000 /$ $\left.\mathrm{mm}^{3}\right)$ and high $\left(>7000 / \mathrm{mm}^{3}\right)$, and then analyzed by Student's $t$-test or Mann-Whitney U-test as appropriate. Other statistical tests such as correlation and logistic regression were used when appropriate. For finding the best cutoff point for leukocyte counts to evaluate the complications, receiver operating characteristic analysis was performed. $P$ value less than 0.05 was considered significant.

\section{Ethical issues}

All patients were informed and signed consent was obtained from patients or from their next of kin prior to the study. The subject's medical information was kept secret during the analysis and all participated as anonymous. The study protocol was evaluated and approved by Tehran University of Medical Sciences Institutional review board.

\section{Results}

In this analytical, cross sectional study, there were 64 (34.8\%) male and 120 (68.2\%) female subjects. The patients' mean age was $55.08 \pm 11.8$ years, and their duration of diabetes from the time of diagnosis was $9.7 \pm 7.3$ years. Average leukocyte count in these patients was $7594 \pm 1965 / \mathrm{mm}^{3}$. Other baseline characteristics are shown in Table 1.

Before using our cutoff point, analyses were done using pure leukocyte count. There was no significant correlation between leukocyte count with serum total cholesterol $(\mathrm{R}=0.01$, $P=0.8)$, triglyceride levels $(\mathrm{R}=0.07, P=0.3)$, and a patient's body mass index (BMI) $(\mathrm{R}=0.50, P=0.5)$. Linear regression model showed that leukocyte count could predict the number of complications in diabetic individuals $\left(\mathrm{R}^{2}=0.55, P<0.001\right)$.

Leukocyte counts had significant difference in patients with and without retinopathy and albuminuria $(P<0.0001)$. Furthermore, the subjects were divided into two groups according to any kind of complication and we found a significant difference in leukocyte counts within these groups $(P<0.0001)$. Receiver operating characteristic analysis was done to find the best cutoff point for leukocyte counts in 
Table I Baseline characteristic of patients

\begin{tabular}{|c|c|c|c|c|c|c|}
\hline & Age (years) & $\begin{array}{l}\text { Diabetes duration } \\
\text { (years) }\end{array}$ & $\begin{array}{l}\text { Cholesterol } \\
(\mathrm{mmol} / \mathrm{l})\end{array}$ & $\begin{array}{l}\text { Triglyceride } \\
\text { (mmol/l) }\end{array}$ & HDL (mmol/l) & LDL (mmol/l) \\
\hline Total & $53 \pm 13$ & $6.9 \pm 6.4$ & $206 \pm 46$ & $210 \pm 119$ & $40.4 \pm 7.1$ & $119 \pm 30$ \\
\hline \multicolumn{7}{|l|}{ Male } \\
\hline $\mathrm{WBC}<7000 / \mathrm{mm}^{3}(\mathrm{n}=53)$ & $54.8 \pm 10.7$ & $8.4 \pm 4.1$ & $208 \pm 46$ & $212 \pm 117$ & $41.1 \pm 13.0$ & $127 \pm 33$ \\
\hline $\mathrm{WBC}>7000 / \mathrm{mm}^{3}(\mathrm{n}=67)$ & $57.9 \pm 115$ & $\mathrm{II} \pm 7.6$ & $206 \pm 36$ & $219 \pm 93$ & $39.3 \pm 9.2$ & $116 \pm 26$ \\
\hline$P$ & 0.129 & 0.048 & 0.778 & 0.702 & 0.351 & 0.183 \\
\hline \multicolumn{7}{|l|}{ Female } \\
\hline $\mathrm{WBC}<7000 / \mathrm{mm}^{3}(\mathrm{n}=35)$ & $52.5 \pm 12.4$ & $8.1 \pm 6.9$ & $210 \pm 45$ & $218 \pm 111$ & $43.3 \pm 13.2$ & $116 \pm 40$ \\
\hline $\mathrm{WBC}>7000 / \mathrm{mm}^{3}(\mathrm{n}=30)$ & $57.0 \pm 7.4$ & $\mathrm{II} .4 \pm 8.4$ & $220 \pm 41$ & $255 \pm 124.5$ & $41.1 \pm 10.0$ & $135 \pm 2 \mid$ \\
\hline$P$ & 0.088 & 0.094 & 0.373 & 0.215 & 0.483 & 0.192 \\
\hline$P$ & 0.02 & 0.009 & 0.835 & 0.322 & 0.191 & 0.815 \\
\hline
\end{tabular}

Notes: Bolded $P$ values are significant.

Abbreviations: HDL, high density lipoprotein; LDL, low density lipoprotein; WBC, white blood count.

relation to any complications. According to this analysis, a leukocyte count of $6750 / \mathrm{mm}^{3}$ with a sensitivity of $80.2 \%$ and a specificity of $56.4 \%$, and a count of $7550 / \mathrm{mm}^{3}$ with a sensitivity of $63.2 \%$ and a specificity of $74.6 \%$ indicated at least one diabetes complication. Our cutoff point of $7000 / \mathrm{mm}^{3}$ had a sensitivity of $73.3 \%$ and a specificity of $66.0 \%$ (area under the curve $=0.778, P<0.0001$ ), (Figure 1).

Leukocyte counts in $88(47.8 \%)$ patients was lower than $7000 / \mathrm{mm}^{3}$ and the other $96(52.2 \%)$ had higher leukocyte counts. Out of all of our patients, $26(14.3 \%)$ had cardiovascular complications; 64 (35.6\%) had albuminuria and 65 (35.9\%) suffered from retinopathy. Only 13 (14.8\%) of the 88 evaluated patients with leukocyte counts under $7000 / \mathrm{mm}^{3}$ were diagnosed with retinopathy; but 53 (55.2\%) out of the 96 patients with leukocyte counts of more than our cutoff point had retinopathy $(P<0.001)$. Albuminuria was evident in $17(19.3 \%)$ of the 88 individuals with low $\left(<7000 / \mathrm{mm}^{3}\right)$

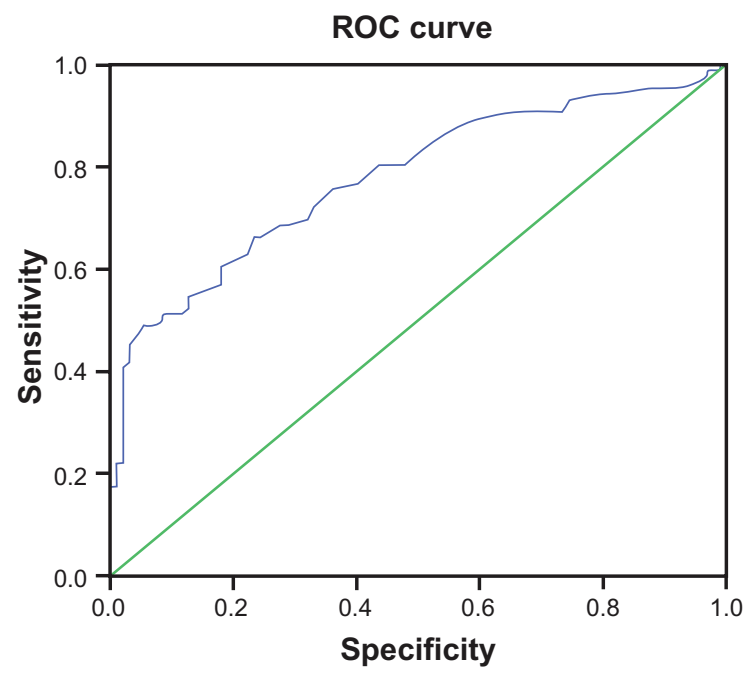

Figure I ROC analysis based on having at least one microvascular complication. Abbreviation: ROC, receiver operating characteristic. leukocyte counts, but it was detected in only 47 (49.5\%) of patients out of 96 with high leukocyte counts $(P<0.001)$.

Ischemic heart disease (IHD) was evaluated in only 100 of the available patients; 26 had a positive history. Only six (12.2\%) out of the 49 patients with low leukocyte counts were in this group, compared with $20(39.2 \%)$ patients with high leukocyte counts and IHD $(P=0.02)$.

There was a statistically significant difference between mean age in the groups with low and high leukocyte counts (53.8 \pm 11.4 versus $57.6 \pm 10.4$ years, respectively, $P=0.02)$; this difference was more significant between the diabetes detection periods in these two groups $(P=0.009)$. Because of this difference, we adjusted our data for age and duration of diabetes using logistic regression and found that this difference was significant only for diabetes duration $(P<0.001$, $\mathrm{R}^{2}=0.326$, odds ratio $=0.829$ ).

There was no significant difference between gender, lipid profile, mean blood pressure, BMI, and smoking history in patients with low or high leukocyte count $(P>0.05)$.

\section{Discussion}

Investigations to find an inflammatory biomarker as an indicator of diabetes complications have been under consideration for some years. Numerous biomarkers have been investigated. ${ }^{11-15}$ In our opinion, the leukocyte count test can be added to the diabetes control protocol as an early predictor beside that of a routine physical examination. Leukocyte count can reflect the inflammatory situation of the whole system. This study was performed to discover whether leukocyte count is a suitable indicator for development of any type 2 diabetes complications.

As the results of this study show, higher leukocyte counts were correlated with both macrovascular and microvascular diabetes complications; it is notable that retinopathy and cardiac events in the group with higher leukocyte levels were 
three times more prevalent, and nephropathy prevalence was more than two times higher in the group with low leukocyte counts. In the present study, there was a relationship between age and diabetes duration to leukocyte count - it can be said that patients with higher leukocyte counts were older and had had diabetes for longer. But some other studies showed different results and demonstrated that age and diabetes duration did not have any significant difference in patients with high or low leukocyte counts..$^{21,22}$ To investigate these counter results, a logistic regression was done to eliminate the influences of each other on these results.

One study showed that fibrinogen as a cardiovascular risk predictor was higher in patients with complications of type 2 diabetes. ${ }^{21}$ Another study supports this result; a relation between $\mathrm{C}$-reactive protein and metabolic syndrome suggested that it could be a part of its criteria. ${ }^{22}$ Knowing that the physiopathology of metabolic syndrome and type 2 diabetes has the same insulin resistance, ${ }^{23-25}$ it can be concluded that inflammatory response can play an important role in the development of diabetes complications.

In a similar cross sectional study in 2004 by Tong et al on 3776 Chinese diabetic patients in Hong Kong, it was demonstrated that leukocyte counts in the normal range were independently related to both micro- and macrovascular complications consisting of retinopathy, nephropathy, and IHD. ${ }^{14}$ Furthermore, the study found that there was a direct relationship between leukocyte count and BMI, mean blood pressure, and lipid profile. Another study conducted in Turin University on 659 Italian patients showed that there was a relationship between leukocyte count and albuminuria. ${ }^{26}$ In another cross sectional study in 2005 by Chung et al on 1480 patients in Taiwan, significant relationships between neutrophils, monocytes, and lymphocytes counts with nephropathy were found, ${ }^{27}$ and later in 2007, Tsai et al demonstrated a relationship between leukocyte count and IHD. ${ }^{28}$ Our results were similar to those findings. The basic conclusion from all of these studies is that a rise in leukocyte count, even within the normal range, can predict the severity of and the number of complications in patients with type 2 diabetes.

These findings, like other studies, demonstrated that inflammatory biomarkers such as higher leukocyte count are related to metabolic syndrome, cardiovascular diseases, and insulin resistance, and provide evidence for the thesis regarding the role of leukocytosis in microvascular and macrovascular complications of diabetes.

Nowadays, scientists believe that inflammatory factors play an important role in the pathogeneses of complications. Chronic inflammation induces development and progression of type 2 diabetes, implying that immunologic and inflammatory mechanisms can play a role in procession of the disease. ${ }^{29,30}$ Another theory is that a low insulin level in the blood stimulates neutrophil production in bone marrow. ${ }^{31,32}$ However, some receptors were found in diabetic patients' immune systems that induce inflammation in blood vessels. ${ }^{33}$ Chronic inflammation responses in addition to other risk factors can help to progress diabetes complications by inducing massive endothelium injury and an increase in some mediators and oxidative stresses. ${ }^{33}$

In this study - as a cross sectional study - a cause-andeffect relationship between leukocyte counts and chronic complications was not determined. Another limitation of this study was that acute viral infections including cytomegalovirus, herpes, or another infection that could not be recognized may have changed the result of leukocyte count as an inflammatory biomarker.

This study did not find any significant difference in BMI, lipid profile, and mean blood pressure between patients with low or high leukocyte counts, but as mentioned above some studies showed that these are related. ${ }^{22,24}$ As an important factor in metabolic syndrome, cardiovascular disease and insulin resistance ${ }^{20,21}$ it is recommended that more work is done to highlight these controversies.

Therefore, leukocyte count can be a cost-benefit laboratory test that can identify diabetic individuals at high risk for micro- and macrovascular complications and can be used to prevent such patients from the possibility of morbid crises.

\section{Conclusion}

An elevated leukocyte count, even within the normal range, is associated with chronic complications in type 2 diabetes. Accompanied by other markers, chronic inflammation that can be shown by this factor could be related to pathogenesis and the progression of these diabetes-related complications. Thus, leukocyte count, as a complete blood count test could be considered as an appropriate clinical examination for early diagnosis and prevention of microvascular and macrovascular complications thus reducing morbidity and mortality from this disease.

\section{Disclosure}

The authors report no conflicts of interest in this work.

\section{References}

1. American Diabetes Association. Standards ofmedical care in diabetes-2011. Diabetes Care. 2011;34(Supp1 1):S11-S61.

2. Dandona P, Aljada A. A rational approach to pathogenesis and treatment of type 2 diabetes mellitus, insulin resistance, inflammation, and atherosclerosis. Am J Cardiol. 2002;90(5A):27G-33G. 
3. King H, Aubert RE, Herman WH. Global burden of diabetes, 1995-2025: prevalence, numerical estimates, and projections. Diabetes Care. 1998;21(9):1414-1431.

4. Johnston SS, Conner C, Aagren M, Smith DM, Bouchard J, Brett J. Evidence linking hypoglycemic events to an increased risk of acute cardiovascular events in patients with type 2 diabetes. Diabetes Care. 2011;34(5):1164-1170.

5. Bunce C, Wormald R. Causes of blind certifications in England and Wales. Eye. 2008;22(7):905-911.

6. Avisar R, Friling R, Snir M, Avisar I, Weinberger D. Estimation of prevalence and incidence rates and causes of blindness in Israel, 1998-2003. Isr Med Assoc J. 2006;8(12):880-881.

7. Cusumano A, Garcia-Garcia G, Di Gioia C, et al. End-stage renal disease and its treatment in Latin America in the twenty-first century. Ren Fail. 2006;28(8):631-637.

8. Insull W Jr. The pathology of atherosclerosis: plaque development and plaque responses to medical treatment. Am J Med. 2009; 122(Suppl 1):S3-S14.

9. Intensive blood-glucose control with sulphonylureas or insulin compared with conventional treatment and risk of complications in patients with type 2 diabetes (UKPDS 33): UK Prospective Diabetes Study (UKPDS) Group. Lancet. 1998;352(9131):837-853.

10. The diabetes control and complications trial research group: The effect of intensive treatment of diabetes on development and progression of long term complications in insulin dependent diabetes mellitus. $N$ Eng J Med. 1993;329(14):997-986.

11. Stamler J, Vaccaro O, Neaton JD, Wentworth D. Diabetes, other risk factors, and 12-yr cardiovascular mortality for men screened in the Multiple Risk Factor Intervention Trial. Diabetes Care. 1993;16(2):434-444.

12. Ross R. Atherosclerosis-an inflammatory disease. $N$ Engl J Med. 1999;340(24):115-126.

13. Weijenberg MP, Feskens EJ, Kromhout D. White blood cell count and the risk of coronary heart disease and all-cause mortality in elderly men. Arterioscler Thromb Vasc Biol. 1996;16(4):499-503.

14. Tong PC, Lee KF, So WY, et al. White blood cell count is associated with macro- and microvascular complications in Chinese patients with type 2 diabetes. Diabetes Care. 2004;27(1):216-222.

15. Heidland A, Sebekova K, Schinzel R. Advanced glycation end products and the progressive course of renal disease. Am J Kidney Dis. 2001;38(4):S100-S106.

16. Vlassara H, Fuh H, Donnelly T, Cybulsky M. Advanced glycation end products promote adhesion molecule (VCAM-1, ICAM-1) expression and atheroma formation in normal rabbits. Mol Med. 1995;1(4):447-456.

17. Vlassara H, Brownlee M, Manogue KR, Dinarello CA, Pasagian A. Cachectin/TNF and IL-1 induced by glucose-modified proteins: role in normal tissue remodeling. Science. 1988;240(4858):1546-1548.

18. Esposito C, Gerlach H, Brett J, Stern D, Vlassara H. Endothelial receptor-mediated binding of glucose-modified albumin is associated with increased monolayer permeability and modulation of cell surface coagulant properties. J Exp Med. 1989;170(4):1387-1407.
19. Andersen JU, Mauricio D, Karlsen AE, Mandrup-Poulsen T, Nielsen JH, Nerup J. Interleukin-1B-induced nitric oxide production from isolated rat islets is modulated by D-glucose and 3-isobutyl-1-methylxanthine. Eur J Endocrinol. 1996;134(2):251-259.

20. American Diabetes Association: Diagnosis and classification of diabetes mellitus. Diabetes Care. 2010;33(Suppl 1):S62-S69.

21. Streja D, Cressey P, Rabkin SW. Associations between inflammatory markers, traditional risk factors, and complications in patients with type 2 diabetes mellitus. J Diabetes Complications. 2003;17(3):120-127.

22. Kang ES, Kim HJ, Ahn CW, et al. Relationship of serum high sensitivity C-reactive protein to metabolic syndrome and microvascular complications in type 2 diabetes. Diabetes Res Clin Pract. 2005;69(2):151-159.

23. Hanley AJ, Karter AJ, Festa A, et al. Factor analysis of metabolic syndrome using directly measured insulin sensitivity: The Insulin Resistance Atherosclerosis Study. Diabetes. 2002;51(8):2642-2647.

24. Cheal KL, Abbasi F, Lamendola C, McLaughlin T, Reaven GM, Ford ES Relationship to insulin resistance of the adult treatment panel III diagnostic criteria for identification of the metabolic syndrome. Diabetes. 2004;53(5):1195-1200.

25. Carr DB, Utzschneider KM, Hull RL, et al. Intra-abdominal fat is a major determinant of the National Cholesterol Education Program Adult Treatment Panel III criteria for the metabolic syndrome. Diabetes. 2004;53(8):2087-2094.

26. Bo M, Massaia M, Raspo S, et al. Predictive factors of in-hospital mortality in older patients admitted to a medical intensive care unit. J Am Geriatr Soc. 2003;51(4):529-533.

27. Chung FM, Tsai JC, Chang DM, Shin SJ, Lee YJ. Peripheral total and differential leukocyte count in diabetic nephropathy: the relationship of plasma leptin to leukocytosis. Diabetes Care. 2005;28(7):1710-1717.

28. Tsai JC, Sheu SH, Chiu HC, et al. Association of peripheral total and differential leukocyte counts with metabolic syndrome and risk of ischemic cardiovascular diseases in patients with type 2 diabetes mellitus. Diabetes Metab Res Rev. 2007;23(2):111-118.

29. Festa A, D’Agostino R Jr, Howard G, Mykkänen L, Tracy RP, Haffner SM. Chronic subclinical inflammation as part of the insulin resistance syndrome: the insulin resistance atherosclerosis study (IRAS). Circulation. 2000;102(1):42-47.

30. Fröhlich M, Imhof A, Berg G, et al. Association between C-reactive protein and features of the metabolic syndrome: a population-based study. Diabetes Care. 2000;23(12):1835-1839.

31. Pécsvarády Z, Fisher TC, Darwin CH, et al. Decreased polymorphonuclear leukocyte deformability in NIDDM. Diabetes Care. 1994;17(1):57-63.

32. Alba-Loureiro TC, Munhoz CD, Martins JO, et al. Neutrophil function and metabolism in individuals with diabetes mellitus. Braz J Med Biol Res. 2007;40(8):1037-1044.

33. Stegenga ME, Vander Crabben SN, Dessing MC, et al. Effect of acute hyperglycaemia and/or hyperinsulinaemia on proinflammatory gene expression, cytokine production and neutrophil function in humans. Diabet Med. 2008;25(2):157-164.

Journal of Inflammation Research

\section{Publish your work in this journal}

The Journal of Inflammation Research is an international, peer-reviewed open-access journal that welcomes laboratory and clinical findings on the molecular basis, cell biology and pharmacology of inflammation including original research, reviews, symposium reports, hypothesis formation and commentaries on: acute/chronic inflammation; mediators of inflamma-

tion; cellular processes; molecular mechanisms; pharmacology and novel anti-inflammatory drugs; clinical conditions involving inflammation. The manuscript management system is completely online and includes a very quick and fair peer-review system. Visit http://www.dovepress.com/ testimonials.php to read real quotes from published authors 